\title{
DIELECTRIC PHENOMENA OF SMOKY QUARTZ, NATURAL AND X-AND $\gamma$-RAY IRRADIATED
}

\author{
RYôITI KIRIYAMA AND SHICHIO KAWAI \\ Department of Chemistry, Faculty of Science, Osaka University
}

\begin{abstract}
Dielectric dispersion of natural smoky quartz was observed in the audio-frequency region at about $400^{\circ} \mathrm{C}$. The enthalpy of activation for the dielectric relaxation was about $50 \mathrm{kcal} / \mathrm{mole}$ in contrast with a value of about $20 \mathrm{kcal} / \mathrm{mole}$ for natural colourless quartz. By thermal bleaching, the enthalpy of activation falls to the value for natural colourless quartz.

Exposed to X-rays, the bleached quart $z$ coloured again and the value of activation enthalpy recovered, and to $\gamma$-rays of about $10^{5}$ to $10^{7} \mathrm{r}$. in total dose, coloration also attained, but the effect was different from that by X-rays. A linear relation was found between the energies of activation and the logarithms of the total doses of irradiation.

Probable molecular mechanisms responsible to these dielectric phenomena were proposed. The rôle of water molecules trapped in the structure was discussed.
\end{abstract}

\section{Introduction}

In the preceding paper ${ }^{1)}$, dielectric dispersion at above room temperature for colourless and transparent natural quartz was discussed from a standpoint of a rôle of water molecules and ions included in some lattice defects as impurities. We have now studied the dielectric dispersion phenomena of smoky quartz, natural and irradiated, at higher temperatures to confirm our previous conclusion on the mechanism of dielectric relaxation. The results on smoky quartz were distinctly different from those on colourless one as had been expected. The present paper is a brief report on these experimental results. 


\section{Experimental method}

The apparatus used was essentially the same as that previous1y reported ${ }^{2)}$. Dielectric dispersion was measured mainly in the audio-frequency region, namely between 0.3 and $10 \mathrm{kc}$, using a set of capacity-resistance bridge and $C-R$ oscillator. In the radiofrequency region, a Q-meter was used. A crystal plate, about 1.5 $\mathrm{mm}$. thick, cut perpendicular to the c-axis was inserted into a platinum-foiled condenser without electrode-pasting.

\section{Specimens and conditions of irradiation}

Crystals of natural smoky quartz from Naégi, Gifu Prefecture, and from Ishikawa, Fukushima Prefecture, Japan were used for the present experiment.

As thermal bleaching occurs above about $300^{\circ} \mathrm{C}$., colourless specimens for $\mathrm{X}$-ray or $r$-ray irradiation were prepared by heating at $500^{\circ} \mathrm{C}$. for several hours.

The conditions of X-ray irradiation were as follows: (1) Unfiltered $\mathrm{CuK}$ radiation at $32 \mathrm{kV} ., 18 \mathrm{~mA}$. with the dose rate of $75 \mathrm{r} /$ min.; the total dose was about $10^{5} \mathrm{r}$. (2) White radiation from tungsten at $45 \mathrm{kV}$., $40 \mathrm{~mA}$. with the dose rate of $240 \mathrm{r} / \mathrm{min}$; the total dose was also $10^{5} \mathrm{r}$. The temperature of the specimen during irradiation increased considerably, especially in the latter case, up to about $100^{\circ} \mathrm{C}$ :

The conditions of $\gamma$-ray irradiation were as follows; 1540 curies of the $\mathrm{Co}^{60}$ source was used. The specimen sealed in a small glass vessel was immersed into a water pool wherein the radiation source had been placed at the bottom and was irradiated for a necessary period of time. Therefore, no temperature elevation took place in this case. The total doses ranged from $5.1 \times 10^{5}$ to $1.5 \times 10^{7} \mathrm{r}$. with the dose rate of $1.1 \times 10^{4}$ to $1.5 \times 10^{5} \mathrm{r} /$ hour. 


\section{Results}

(1) Natural smoky quartz. A representative result of the dielectric dispersion along the $c$-axis for natural smoky quartz is shown in Fig. 1, and clearly indicates that the temperature at which the dispersion appears for smoky quartz is much higher than that for colourless one. The activation energies and entropy calculated from the observed data according to Eyring's relation for dielectric relaxation are listed in Table 1 . The activation enthalpy, $\Delta H^{*}$, for smoky quartz was also much higher than that of colourless one. However, the bleached specimen gave a small value of activation enthalpy, which was nearly equal to that of natural colourless one, as shown in Table 1 . The dispersion region of bleached but originally smoky quartz is also found in the same
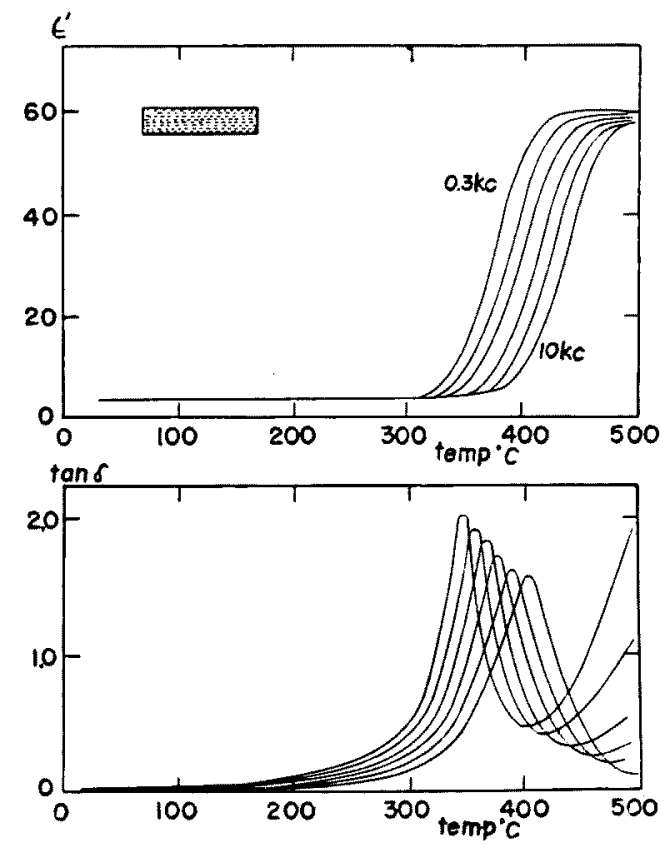

Fig. 1. Dielectric dispersion of a natural smoky quartz at $0.3,0.5,1.0,3.0,5.0$ and $10.0 \mathrm{kc}$. 
Table 1. Activation energies and entropy for dielectric relaxation of natural quartz.

\begin{tabular}{l|c|c|cc}
\multicolumn{1}{c|}{ Specimen } & $\begin{array}{c}\Delta H^{*} \\
\text { (kcal/mole) }\end{array}$ & $\begin{array}{c}\Delta F^{*} \\
\text { (kcal/mole) }\end{array}$ & \multicolumn{2}{|c}{$\begin{array}{c}\Delta S^{*} \\
(\mathrm{E} . \mathrm{U} .)\end{array}$} \\
\hline Smoky (Naégi, No. 1) & 59.0 & 24.6 & 50 at $685^{\circ} \mathrm{K}$ \\
Smoky (Naégi, No. 2) & 38.0 & 24.9 & 20 & 673 \\
Smoky (Ishikawa) & 55.9 & 24.5 & 47 & 663 \\
Bleached (Naégi, No. 1) & 26.3 & 20.9 & 10 & 568 \\
Colourless (Brazil) & 21.3 & 18.4 & 6 & 503 \\
\hline
\end{tabular}
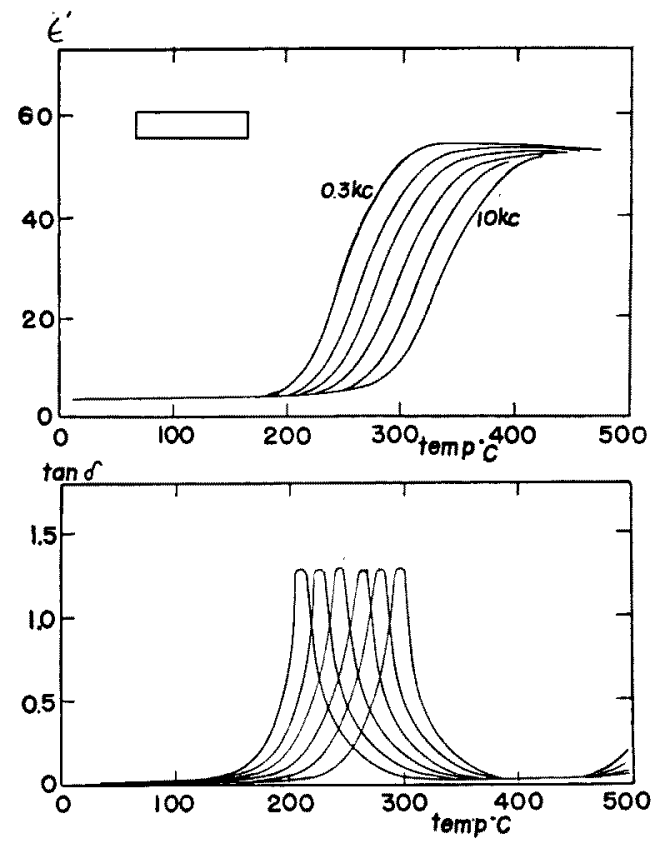

Fig. 2. Dielectric dispersion of a bleached quartz at $0.3,0.5,1.0,3.0,5.0$ and $10.0 \mathrm{kc}$.

temperature region as that of natural colourless one. The feature of the dielectric dispersion is shown in Fig. 2.

(2) Coloured smoky quartz caused by $X$-ray irradiation. Homogeneous coloration could not be attained in the bleached specimen 


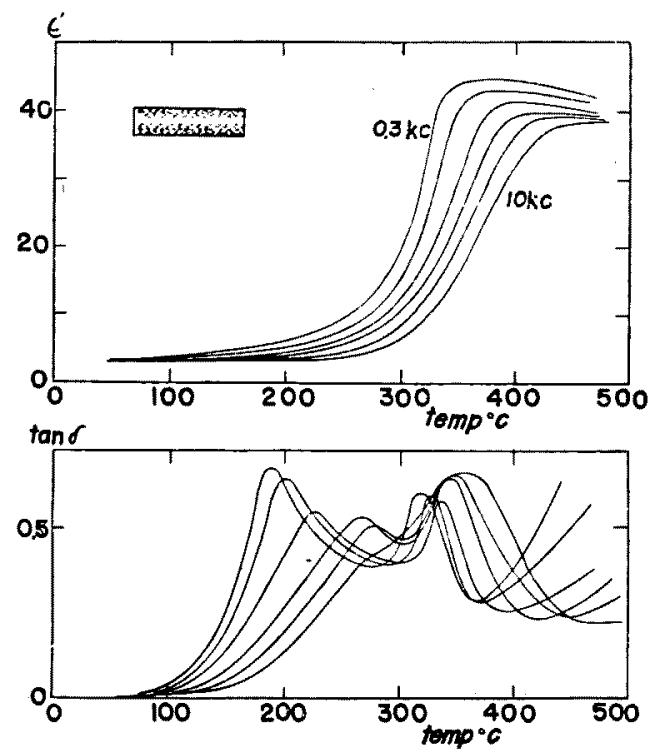

Fig. 3. Dielectric dispersion of an artificially smoked quartz with $\mathrm{X}$-rays of $\mathrm{CuK}$ radiation at $0.3,0.5,1.0,3.0,5.0$ and $10.0 \mathrm{kc}$.

Table 2. Activation energies and entropy for dielectric relaxation of irradiated quartz which was originally smoky and bleached at $500^{\circ} \mathrm{C}$.

\begin{tabular}{|c|c|c|c|c|c|}
\hline \multirow{2}{*}{ Radiation } & \multicolumn{2}{|c|}{ Condition of irradiation } & \multirow{2}{*}{\multicolumn{2}{|c|}{$\begin{array}{c}\Delta H^{*} \Delta F^{*} \\
\text { (kcal/mole) }\end{array}$}} & \multirow{2}{*}{$\begin{array}{c}\Delta S^{*}\left(\text { at }{ }^{\circ} \mathrm{K}\right) \\
\quad(\text { E. U. })\end{array}$} \\
\hline & dose rate & total dose & & & \\
\hline $\begin{array}{l}\text { X-rays, } \mathrm{Cu} K \\
32 \mathrm{kV} ., 18 \mathrm{~mA} .\end{array}$ & $75 \mathrm{r} / \mathrm{min}$ & $10^{5} \mathrm{r}$. & $\begin{array}{ll}58.5 & 2 \\
17.2 & 2\end{array}$ & $\begin{array}{l}23.1 \\
22.2\end{array}$ & $\begin{array}{r}58(613) \\
-10(523)\end{array}$ \\
\hline $\begin{array}{l}\text { X-rays, W, } \\
45 \mathrm{kV}, 40 \mathrm{~mA} .\end{array}$ & $240 \mathrm{r} / \mathrm{min}$ & $10^{5}$ & 45.0 & 23.3 & $35(614)$ \\
\hline \multirow[t]{4}{*}{$\gamma$-rays (No. 1 ) } & $1.1 \times 10^{4} \mathrm{r} / \mathrm{h}$ & $5.1 \times 10^{5}$ & 26.4 & 21.4 & $9(563)$ \\
\hline & $6.0 \times 10^{4}$ & $1.7 \times 10^{6}$ & $32.9 \quad 2$ & 22.0 & $19(583)$ \\
\hline & $3.1 \times 10^{4}$ & $2.2 \times 10^{6}$ & $34.4 \quad 2$ & 22.7 & $19(593)$ \\
\hline & $3.1 \times 10^{4}$ & $5.9 \times 10^{6}$ & 40.12 & 23.2 & $28(613)$ \\
\hline \multirow[t]{2}{*}{ (No. 3) } & $6.0 \times 10^{4}$ & $4.0 \times 10^{6}$ & $32.2 \quad 2$ & 23.0 & $16(583)$ \\
\hline & $1.5 \times 10^{5}$ & $1.5 \times 10^{7}$ & $44.4 \quad 2$ & 24.1 & $33(613)$ \\
\hline
\end{tabular}


by $\mathrm{Cu} K$ radiation owing to the poor penetrating power of the $\mathrm{X}$ rays into the crystal. In spite of irradiation from both sides, a colourless zone remained in the middle part of the specimen as shown schematically at the corner of Fig. 3 . In this case, two kinds of dispersion of $\tan \delta$ were observed (Fig. 3); one found in the lower temperature region obviously due to the colourless zone in the middle part and the other in the higher temperature region due to the smoky surface-zones. Each of the values of activation energy listed in Table 2 is in a fair agreement with the value for natural colourless quartz and that for natural smoky one, respectively.

With white radiation from tungsten, homogeneous coloration was attained, the lower temperature dispersion just described above being scarecely observed. The feature of dispersion curves is quite
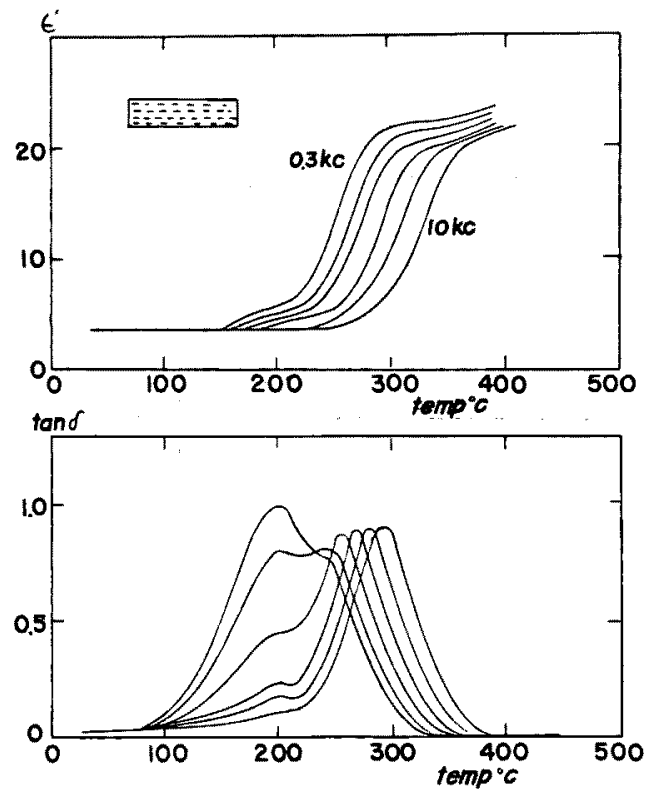

Fig. 4. Dielectric dispersion of a moderately $\gamma$-ray irradiated $\left(5 \times 10^{5} \mathrm{r}\right.$.) quart $z$ at $0.3,0.5,1.0,3.0,5.0$ and $10.0 \mathrm{kc}$. 
similar to that of natural smoky quartz.

(3) r-ray irradiated quartz. Homogeneously coloured, smoky quart $z$ was obtained by $r$-rays. The dielectric dispersion of a moderately exposed specimen $\left(5.1 \times 10^{5} \mathrm{r}\right.$.) is shown in Fig. 4. There are also two kinds of dispersion of dielectric loss, but the feature of the curves is considerably different from that of X-ray irradiated one. On the low temperature side, a distinctly frequencydependent but temperature-independent dispersion was found at about $200^{\circ} \mathrm{C}$. This characteristic dielectric loss may be attributed to some kind of conduction, presumably conduction of protons liberated from the water molecules by the moderate $\gamma$-ray irradiation. The feature of dispersion observed on the high temperature side resembles that of natural smoky quartz.

Specimens strongly exposed with $\gamma$-rays of about $6 \times 10^{6} \mathrm{r}$. gave single dispersion in the higher temperature region as shown in
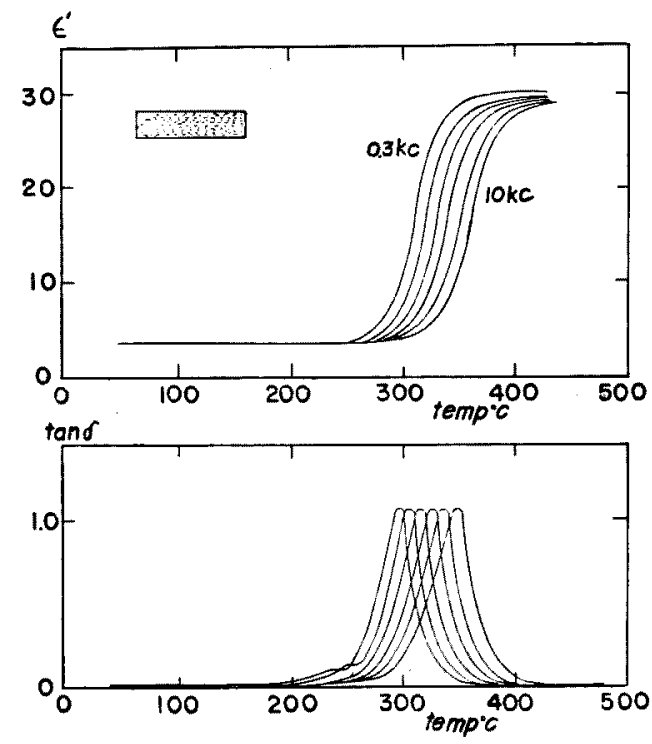

Fig. 5. Dielectric dispersion of a strongly $\gamma$-ray irradiated $\left(6 \times 10^{6} \mathrm{r}\right.$.) quartz at $0.3,0.5,1.0,3.0,5.0$ and $10.0 \mathrm{kc}$. 
Fig. 5. This phenomenon is apparently similar to that found for natural smoky quartz.

Thermodynamical data of activation for the specimens irradiated under various conditions are listed in Table 2 . It is remarkable that the stronger the total dose of $r$-irradiation is, the larger is the energy of activation for dielectric relaxation in the higher temperature region.

Approximately linear relations between energies of activation, or entropies of activation, and the logarithms of total doses were found in our experimental range of $\gamma$-irradiation (Fig. 6). One

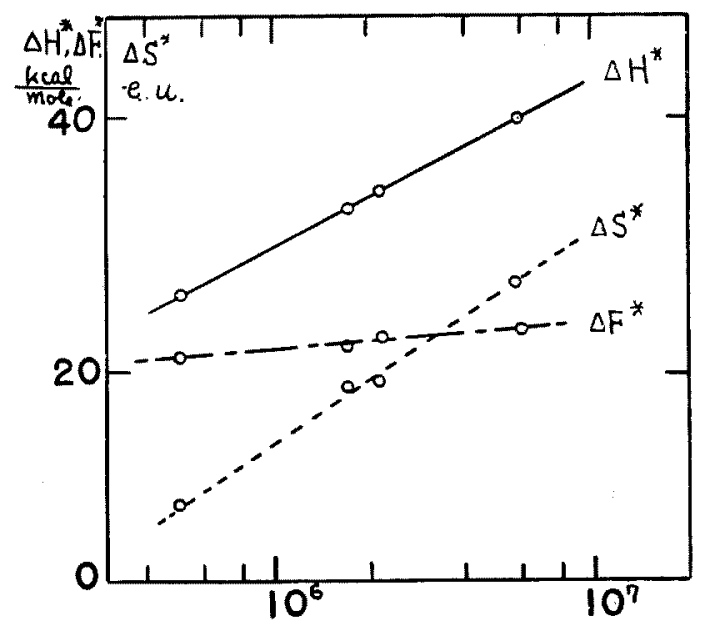

Fig. 6. Linear relations between energies of activation, or entropy of activation, and logarithms of total doses.

specimen originally smoky in colour was used throughout the measurements and bleaching by heating and colouring by irradiation were repeated alternately. Another specimen was examined to confirm the result and such a linear relation was also obtained although the slopes of the lines were not identical with those for the former. 


\section{Discussion}

In the case of X-ray irradiation, the linear relation between the activation energies and the logarithms of the doses has not been found. Moreover, the enthalpy of activation for dielectric relaxation at higher temperatures has a fixed value irrespective of the kinds of X-ray sources and is larger than that for any one of the $r$-ray irradiated specimens.

These facts suggest that the effect caused in the crystal lattice by $\mathrm{X}$-rays is considerably different from that by $\gamma$-rays. Then, two different molecular mechanisms should be proposed.

The most appropriate explanation for the linear relation may be to postulate some sort of lattice distortion. Although no evidence of lattice distortion in $\gamma$-ray irradiated quartz has yet been reported ${ }^{3)}$, the radiation energy of $\gamma$-rays from the $\mathrm{Co}^{60}$ source is much higher than the threshold value of radiation energy for producing atomic displacements ${ }^{4}$. It is reasonable, therefore, that the more intense the dose of irradiation is the more easily are displaced the atoms in the structure, thus rendering the diffusion of impurity ions parallel to the c-axis which is the direction of the spiral axis, more and more difficult as shown schematically in Fig. 7. Consequently, the energy of activation for the ionic displacement or drift to the direction of the applied electric field should be increased gradually with deformation of the trapping cage in the threediemensional network.

Once heated up to $500^{\circ} \mathrm{C}$. anneal-

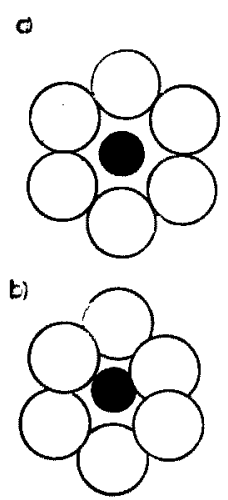

Fig. 7. Schematic model of lattice distorsion projected on the basal plane. The black circle indicates the impurity ion enclosed in the tunnel of quartz lattice. The large open circle indicates oxygen atom of Si-O framework. 


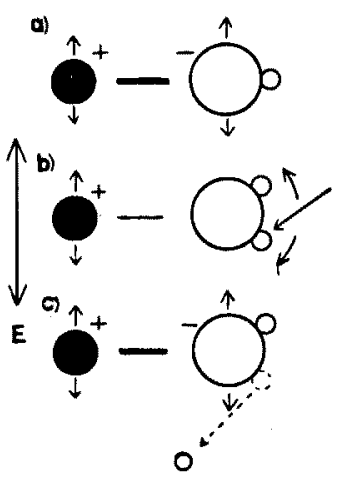

Fig. 8. Schematic models of the interaction of the impurities in quartz lat. tice.

a) In smoky quartz, $\mathrm{Na}^{+}$ and $\mathrm{OH}^{-}$are mutually interact with ion-ion interaction.

b) By heating, recombination of $\mathrm{OH}^{-}$and $\mathrm{H}^{+}$ occurs and $\mathrm{OH}_{2}$ molecule is formed.

c) By absorbing X-rays, strictly speaking by the recoiled electron, $\mathrm{OH}_{2}$ molecule dissociates to $\mathrm{OH}^{-}$and $\mathrm{H}^{+}$. The ionion interaction reco. vers.

ing takes place, so that the value of activation energy recovers.

The effect of X-ray irradiation is quite different from that of $r$-ray irradiation mentioned above. The water molecule trapped in some lattice defects may be dissociated by X-ray to $\mathrm{H}^{+}$and $\mathrm{OH}^{-}$. This proton, $\mathrm{H}^{+}$, has a relatively low kinetic energy and will be readily captured by a neighbouring oxygen atom in the threedimensional Si-O framework, forming a metastable Si-O-H bond. The $\mathrm{OH}^{-}$ ion will interact with an alkali ion, e. g. $\mathrm{Na}^{+}$, included nearby in a lattice defect as impurity (see Fig. 8). The ion-ion interaction between $\mathrm{Na}^{+}$and $\mathrm{OH}^{-}$is much larger than the iondipole interaction between $\mathrm{Na}^{+}$and an $\mathrm{OH}_{2}$ molecule in colourless quartz. Thus the energy of activation jumps suddenly by X-ray irradiation from a value of $20 \mathrm{kcal} / \mathrm{mole}$ up to about 50 $\mathrm{kcal} / \mathrm{mole}$. The effect of heating should give the chance of recombination of the free $\mathrm{OH}^{-}$with $\mathrm{H}^{+}$which has been unstably combined with an oxygen atom. Therefore, the recovery of the dielectric phenomena by heating takes the course observed in our experiment.

It is believed that natural smoky quartz usually found in pegmatite has been coloured by natural $\gamma$-rays during a long geological period below the bleaching temperature. However, the $r$ rays must have been softened in a marked degree by scattering and absorption in the surrounding rock-forming minerals before 
the rays reached into the crystal surface. Accordingly, the dielectric phenomena for natural smoky quartz may be similar to those for the specimen artificially smoked by X-rays rather than by $\gamma$-rays.

\section{REFERENCES}

1) Kiriyama, R. and S. Kawai: Jour. Mineral. Soc. Japan, 3, 609 (1958) (in Japanese).

2) Kiriyama, R., H. Ibamoto, M. Koizumi and R. Kitagaki : Mineral. Jour., 1, 313 (1955).

3) Kinchin, G.H. and R.S. Pease: Rep. Prog. Physics, 18, 37 (1955).

4) Diens, G. J. and G. H. Vineyard: Radiation effects in solids, 50 ; 58, Interscience Pub. New York (1958).

Manuscript received Sept. 28, 1959. 